primary health care visits of asthma sufferers in an area with air pollution levels well within the standard air quality guidelines.

Methods Hourly readings of ambient particulate matter $\left(\mathrm{PM}_{10}, \mathrm{PM}_{2.5}\right)$, nitrogen dioxide $\left(\mathrm{NO}_{2}\right)$, nitrogen oxide $(\mathrm{NO})$, ozone $\left(\mathrm{O}_{3}\right)$ and sulphur dioxide $\left(\mathrm{SO}_{2}\right)$ from the Swedish Meteorological and Hydrological Institute (SMHI) from 2005 to 2010 were used. Six different metrics were created from these hourly readings: (1) daily 1 -h maximum; (2) 24-h average; (3) commuting-period; (4) daytime average; (5) night-time average; and (6) the daily 8 -h maximum. Outcome data were obtained from a regional health care database, covering approximately half a million people living in Malmö and neighbouring municipalities. Poisson generalised linear models were used to examine the relations between daily primary health care (PHC) visits due to asthma and air pollution metrics with different time lags.

Results Air pollutant levels throughout the study period remained well within the WHO air quality guidelines $\left(\mathrm{PM}_{10}\right.$ daily mean of $16.4 \mu \mathrm{g} / \mathrm{m}^{3}$ ). A consistent relation between daily PM levels and PHC visits due to asthma was observed for all metrics. An increased risk of $11 \%$ was found with every 10 -unit increase in daily mean levels of $\mathrm{PM}_{10}$. Commuting-period and daytime concentrations of $\mathrm{PM}_{10}$ were also associated with increased risks, of $10 \%$ and $9 \%$, respectively. The increased risk was moderate for the 8 -hour $(8 \%)$ and night-time $(7 \%)$ metrics. The lowest risk was observed for the 1 -hour maximum value $(3 \%)$.

Conclusions The results suggest that air pollution has adverse effects on respiratory health, even at very low concentrations. A significant variation in risk was observed during the day depending on the metric used. The results of this study highlight the need to re-assess air quality guidelines.

\section{RELEVANCE OF EXPOSURE TO CLEANING AGENTS BEYOND CLEANING PROFESSIONALS: PRIVATE HOMES AND HEALTHCARE WORKERS}

${ }^{1} \mathrm{~N}$ Le Moual, ${ }^{1}$ Bédard, 'Dumas, 'Varraso, 'Kauffmann, ${ }^{2}$ Zock. 'Inserm, Villejuif, France; ${ }^{2}$ CREAL, IMIM, Barcelona, Spain

\subsection{6/oemed-2013-101717.77}

Workplace and home exposures to cleaning products constitute an emerging health issue. The aim is to address the potential adverse role of exposure to cleaning agents on asthma in private homes and healthcare workers. Regarding healthcare workers, recent publications showed that they may be exposed to high level of cleaning products. As a cause of concern, they underestimated their exposures and appeared as a high risk group for asthma. Regarding home cleaning, two studies have published on this topic and suggested a deleterious role of the frequent use of cleaning sprays on asthma activity and incidence. One of them suggested a possible avoidance of spray use by women with asthma.

More recently, in a nested case-control survey on asthma of French women from the 'Etude Epidémiologique auprès des femmes de la MGEN' (E3N study), we investigated the association between self-reported weekly use of cleaning products (evaluated as previously) and current asthma among 570 women (235 with current asthma and 335 without asthma; 68 years, $59 \%$ never smokers). A positive association was suggested between weekly use of at least one spray and current asthma (odds ratio [95\% confidence interval] adjusted for age, diploma, body mass index and smoking status: 1.45 [0.94-2.24], $\mathrm{p}=$ 0.09), with a significant association in women without cleaning help (1.86 [1.04-3.33]). Avoidance of polluted places was significantly more frequent in women with current asthma who had at least two symptoms.

Domestic exposure to cleaning sprays may represent an important public health issue especially in women and it may be important to limit their use. Female hospital workers are exposed to numerous cleaning products at high risk for asthma. Selection bias may be important for both domestic and workplace exposures. More work is needed to identify the underlying mechanism (allergic or non-allergic) and to have accurate estimates of cleaning agents.

\section{THE CHANGING EPIDEMIOLOGY OF SILICOSIS IN SOUTH AFRICAN GOLD MINING - AN INDUSTRY WIDE STUDY}

${ }^{1} \mathrm{D}$ H Knight, ${ }^{2}$ Ehrlich, ${ }^{3}$ Fielding, ${ }^{3}$ Jeffery, ${ }^{3}$ Grant, ${ }^{4}$ Churchyard. ${ }^{1}$ Uni Cape Town/ International SOS, Cape Town, South Africa; ${ }^{2}$ University Cape Town, Cape Town, South Africa; ${ }^{3}$ LSTMH, London, United Kingdom; ${ }^{4}$ Aurum Health Institute, Johannesburg, South Africa

\subsection{6/oemed-2013-101717.78}

Objectives Against the background of an epidemic of silicosis and related tuberculosis revealed by field and autopsy studies in recent decades, the South African gold mining industry has committed itself to the elimination of silicosis.

Methods Annual chest radiographs of active miners were taken by mine occupational health services. These were collected in a representative sample of miners enrolled into a baseline survey between 2004 and 2009 as part of a cluster randomised trial of community-wide isoniazid preventive therapy. All radiographs were read for silicosis by an experienced lay reader. All images classified as abnormal and a random sample of normals was reread by a 'B' reader for validation.

Results A total of 14322 radiographs from 15 goldmining shafts from three companies were read by the lay reader for an overall silicosis prevalence of $3.7 \%$ (> ILO 1/1), reaching 6.6\% for workers with $>20$ years since first employment. Silicosis prevalences adjusted for the readings of the B-reader were much lower: 1.7\% and $3.2 \%$ respectively. On either reading, these industry-wide radiological prevalences are lower than single workforce surveys dating from 2000/2001. They are also at considerable variance with statutory autopsy data from in-service black miners.

Conclusions In the absence of evidence of lower dust levels in gold mines in the decades prior to this study, one explanation for these findings is that goldminers with silicosis are increasingly being selected out of the industry by ill-health, particularly HIV and tuberculosis, and/or by stricter hiring practices in a declining industry. High silicosis prevalence is thus likely still to be found among former goldminers. Autopsy data from active miners further suggest a shift towards sub-radiological silicosis, which has been shown to confer a substantially increased risk of tuberculosis even in the absence or radiological disease.

\section{UK BIOBANK: USE AND EXTENSION OF OCCUPATIONAL INFORMATION TO INVESTIGATE OCCUPATIONALLY- RELATED CHRONIC OBSTRUCTIVE PULMONARY DISEASE (COPD) IN THE UK}

'L Rushton, ${ }^{2}$ Sadhra, 'De-Matteis, 'Jarvis, ${ }^{3}$ Fishwick, ${ }^{4}$ Chambers, ${ }^{5}$ Mitchell, ${ }^{5}$ Gallacher, ${ }^{1}$ Wheatley, 'Hutchings, ${ }^{1}$ Cullinan. ${ }^{1}$ Imperial College London, London, United Kingdom; ${ }^{2}$ University of Birmingham, Birmingham, United Kingdom; ${ }^{3}$ University of Sheffield, Sheffield, United Kingdom; ${ }^{4}$ Health and Safety Laboratory, Buxton, United Kingdom; ${ }^{5}$ University of Cardiff, Cardiff, United Kingdom

10.1136/oemed-2013-101717.79 
Objective To investigate the causes and burden of work-related COPD in the UK through the use and extension of UK Biobank cohort information on occupational exposure.

Methods UK Biobank is a population-based cohort of over 500,000 people aged between 40-69 years and recruited in 2006-2010. Baseline measurements of spirometric lung function and lifetime smoking history have been collected and are being analysed with information on current employment status translated into standard occupational codes (SOC 2000). An enhanced web-based occupational module based on the hierarchical structure of SOC 2000 will be sent to all participants in 2013 to collect their life-time occupational histories. Subsidiary questions concerning industries, jobs and exposures related to COPD will be included, as well as questions on shift patterns and hours worked. We are developing a general Job Exposure Matrix (JEM) for COPD for application to the Biobank data. The JEM involves allocation of exposure for different airborne pollutant types for each 4 digit SOC code. Results from systematic review and evaluation of the literature on occupational COPD and the currently available disease-specific JEMs are being used to identify key jobs, exposures and occupational burden of COPD.

Results About $40 \%$ of participants have never smoked. At baseline, only $8352(1.67 \%)$ reported that they had been given a diagnosis of chronic bronchitis or emphysema by a doctor. Spirometry data are available for approximately 324000 participants. Preliminary analysis indicates that 30214 men and 25608 women have airflow obstruction (FEV1/FVC <0.7). Of these, $39 \%$ of the women reported never smoking in contrast to about $3 \%$ of the men.

Conclusions This project will provide estimates of the burden of COPD atributable to lifetime occupational exposure in the UK and facilitate the development of a long-term strategy for the prevention of occupational COPD.

\section{CROSS-SECTIONAL STUDY ON RESPIRATORY SYMPTOMS IN WORKERS EXPOSED TO METALWORKING FLUID AEROSOLS}

Brisman, Olin, Andersson, Hammar, Dahlman-Höglund. Sahlgrenska University Hospital \& Academy, Gothenburg, Sweden

\subsection{6/oemed-2013-101717.80}

Objectives To survey which respiratory symptoms are more prevalent in workers exposed to metalworking fluids (MWF) in machine shops compared with referents. Workers with common symptoms from the lower airways will be invited to clinical examinations.

Methods Workers in two large companies answered questionnaires on respiratory symptoms, atopy, working conditions and smoking. Most questions were used in a previous Swedish study of MWF exposed workers (Lillienberg et al, 2010). In each company there were workers exposed to MWF and referents from similar machine shops but not exposed to MWFs. There were 480 MWF exposed workers and 142 non-exposed referents answering the questionnaire. The response rate was $83.6 \%$. $88.7 \%$ of the respondents were male. Prevalence of different symptoms and atopy were compared between exposed and referents by chi-square tests or Fisher's exact test.

Results In general, there were higher prevalences of symptoms in exposed workers. The prevalence of dry cough was $37.7 \%$ in exposed workers vs. $27.5 \%$ in referents $(p=0.0006)$. Prevalence of often occurring self-reported symptoms such as cough, dyspnoea or wheeze when exposed to MWF was $6.2 \%$, and occasional such symptoms was reported by $22.6 \%$ of MWF exposed respondents. There were no significant difference in atopy or never smokers between exposed and referents. Prevalences of current symptoms from eyes, nose and lower airways were higher in exposed workers than in referents and similar as in the previous Swedish study.

Conclusions Metal workers exposed to MWFs reported more respiratory and eye symptoms than blue collar referents from the same companies. In particular, dry cough was significantly more common. MWF exposed workers and referents with dry cough or asthma as well as exposed workers and referents without symptoms will be invited for clinical examinations.

\section{HOW RELIABLE IS A 'YES' AFTER TEN YEARS?}

B E Andersson, Holm, Nilsson, Torén. Sahlgrenska University Hospital, Gothenburg, Sweden

\subsection{6/oemed-2013-101717.81}

Objectives When doing prospective incidence studies of e.g. asthma in the general population using questionnaires, they are often repeated with an interval of five or ten years. We commonly use questions like "Have you ever had asthma?" Reliability usually is studied as test-retest reliability assuming the same conditions. But how reliable is an affirmative response of a question of ever having had a condition after ten years?

Methods In a study of incidence and risk factors of respiratory diseases a random sample of 20000 individuals in a county in Western Sweden born between 1943 and 1973 was sent a questionnaire in 1993. It comprised items about airway symptoms and smoking. 15813 subjects answered (79\%) and at follow-up in 200311463 of them (72\%) answered the questionnaire. The proportion of a yes answer on the second occasion, conditional on having answered yes on the first occasion, with confidence intervals $(95 \% \mathrm{CI})$ was calculated by gender and baseline age groups (20-30 years, 31-40 years, $41-50$ years).

Results The proportion reporting physician-diagnosed asthma 2003 when doing so 1993 was $84.1 \%$ (418/497, 95\% CI 80.687.2). Corresponding figures for reporting "ever had asthma" was $84.2 \%(534 / 634,95 \%$ CI 81.2-87.0), "ever had wheeze since the age of 15 " was $55.3 \%(1109 / 2005$, 95\% CI $53.1-$ 57.5), ever smoking was $93.9 \%$ (5161/5496, 95\% CI 93.294.5). The proportion reporting physician-diagnosed asthma by gender: women $85.7 \%$ (95\% CI 81.1-89.6) and men $82.0 \%$ (95\% CI 76.2-86.9).

Conclusion In this general population study the proportion of an affirmative response of a question of ever having had a condition after ten years, conditional on having answered yes on the first occasion, differed depending of question but not due to gender or age. Ever smoking and asthma were highly reliable in this aspect. There was no difference between reported asthma and physician-diagnosed asthma.

\section{HIGH RESOLUTION COMPUTED TOMOGRAPHY OF THE LUNGS OF ASPHALT WORKERS}

${ }^{1} \mathrm{G}$ Randem, 'Aaløkken, ${ }^{2}$ Ulvestad. 'Oslo University Hospital, Oslo, Norway; ${ }^{2}$ Statens Arbeidsmiljøinstitutt, Oslo, Norway

10.1136/oemed-2013-101717.82 